\title{
1996 Annual Report
}

\author{
Price-Anderson
}

Nuclear Safety Enforcement Program

Office of Enforcement and Investigation

Environment, Safety and Health

U. S. Department of Energy

\section{January 1996}


This document may be obtained from the following sources:

Available to DOE and DOE contractors from the Office of Scientific and Technical Information, P.O. Box 62, Oak Ridge, TN 37831; (615) 576-8401.

Available to the public from the U.S. Department of Commerce, Technology Administration, National Technical Information Service, Springfield, VA 22161; (703) 487-4650.

Also available via the Internet from the DOE Office of Enforcement and Investigation Home Page: http://tis-nt.eh.doe.gov/enforce/

\begin{abstract}
Any comments concerning DOE's Enforcement Program may be directed to Keith Christopher, Director, DOE Office of Enforcement and Investigation, EH-10, CXXI/3 - Room 305, 19901 Germantown Rd., Germantown, MD 20874-1290; (301) 903-0100.
\end{abstract}




\title{
U.S. Department of Energy \\ Nuclear Safety Enforcement Program \\ 1996 Annual Report
}

\author{
Strategic Direction for \\ Price Anderson Enforcement Program
}

The first full year of the Department of Energy Price Anderson Enforcement Program has demonstrated its effectiveness in holding contractors accountable for the safety of operations.

This effectiveness is built on an approach to enforcement that departs from traditional efforts. The DOE program has been designed to encourage full participation and recognition of efforts by field office and contract managers. Enforcement actions can and have been mitigated if the contractor identifies and reports potential safety violations and takes prompt and comprehensive corrective action. Another important feature is that the Headquarters Enforcement Staff is supported by coordinators and technical advisors in Field and Program Offices.

Lessons learned during this first year will shape further improvements. The DOE Enforcement Program, along with safety and health contract clauses, standards and requirements for safety, and independent oversight, are designed to provide an efficient and effective set of tools that set clear expectations and establish accountability.for safety performance at DOE facilities.

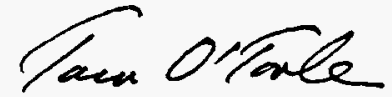

Tara O'Toole, M.D., M.P.H. Assistant Secretary

Environment, Safety and Health 


\section{DISCLAMMER}

Portions of this document may be illegible in electronic image products. Images are produced from the best available original document. 


\section{Table of Contents}

I. HIGHLIGHTS FOR 1996

II. ENFORCEMENT PROGRAM OVERVIEW 3

Background $\quad 3$

Administration $\quad 3$

Noncompliance Identification and Reporting 4

Enforcement Decisions $\quad 4$

Enforcement Process $\quad 5$

III. ACCOMPLISHMENTS $\quad 7$

1. INFRASTRUCTURE DEVELOPMENT $\quad 7$

DOE and Contractor Coordinators $\quad 7$

Nuclear Safety Noncompliance Information System $\quad 8$

Guidance Documents Issued $\quad 8$

Training $\quad 9$

Nuclear Safety Hotline $\quad 9$

Information Dissemination $\quad 9$

2. NONCOMPLIANCES, INVESTIGATIONS AND ENFORCEMENT ACTIONS 9

Cases Considered $\quad 9$

Investigations/Reviews With No Enforcement Action $\quad 10$

$\begin{array}{ll}\text { Notices of Violation and Civil Penalties } & 10\end{array}$

IV. SUMMARY OF SIGNIFICANT ENFORCEMENT ACTIONS 13

Radiological Control Program Violations at Rocky Flats $\quad 13$

Extremity Radiation Dose at Hanford $\quad 14$

Operating With Disabled Criticality Safe Tank at PNNL 14

Uncontrolled Radiation Field at Sandia National Lab 15

V. EXAMPLES WHERE ENFORCEMENT ACTION WAS DEFERRED 17

$\begin{array}{ll}\text { Revamped Contamination Control Program at Mound } & 17\end{array}$

Improved Work Controls at Westinghouse-Hanford $\quad 17$

Improving Compliance With Radiological Postings

at Brookhaven National Laboratory

IV. CHANGES \& IMPROVEMENTS 21

Enforcement Policy Revision $\quad 21$

NTS Reporting Thresholds $\quad 21$

Consistent Field Office Involvement $\quad 22$

Contractors With Less Initiative in Identification and Reporting 23

Table IV-1, FIELD OFFICE INVOLVEMENT $\quad 25$

Table IV-2, CONTRACTOR NTS REPORTING 26 


\section{HIGHLIGHTS}

This first annual report on DOE's PAAA ${ }^{1}$ enforcement program covers the activities, accomplishments and planning for calendar year 1996, but also includes the infrastructure development activities of 1995. It encompasses the activities of not only the headquarters' Office of Enforcement and Investigation (referred to in this report as EHEnforcement), in the Office of Environment, Safety and Health $(\mathrm{EH})$, but also the numerous coordinators and technical advisors in DOE's Field and Program Offices and other EH Offices.

During the first year of the enforcement program's operation, DOE has issued civil penalties totaling $\$ 117,500$ for cases involving significant or potentially significant worker safety violations. A number of other potentially significant cases were evaluated during this same period, but no enforcement action was taken because of contractor initiative in self-identification and prompt corrective actions. These cases are described in subsequent sections of this report.

DOE's nuclear safety requirements are published in various current and forthcoming federal regulations, and establish the requirements for DOE's contractors, subcontractors and suppliers to ensure their activities are conducted in a manner that protects worker and public safety and the environment. DOE's Enforcement Program provides a mechanism to selectively take action where a contractor is in violation of DOE's nuclear safety requirements. DOE's enforcement provisions, embodied in $10 \mathrm{CFR}$ Part 820 and in the Enforcement Policy of Appendix A, are based on a philosophy of encouraging contractor ownership of safety

1 PAAA - 1988 Price Anderson Amendments Act, requiring $D O E$ to enforce compliance with its nuclear safety requirements. and compliance with DOE nuclear safety requirements, through mitigation of enforcement action where contractors demonstrate appropriate initiative in general safety management performance, selfidentification of deficiencies, reporting of these to DOE, and prompt and comprehensive corrective actions for the deficiencies identified. Where such action on the part of the contractor is not adequate, DOE may take enforcement action in the form of issuing Notices of Violation and imposing civil penalties. $^{2}$

This approach to enforcement is expected to be both more effective as well as more efficient than more long-established enforcement programs in other agencies. The objective of motivating contractors to self-identify and correct deficiencies places ownership of safety more squarely on the shoulders of the contractors. This approach is in lieu of large numbers of DOE inspectors trying to find the noncompliances and having contractors simply respond to what is identified. DOE will need to continue a sufficient level of independently identifying noncompliances and taking enforcement action to provide adequate incentive for contractors to implement aggressive and proactive safety programs.

DOE's enforcement program implements the provisions of the Price-Anderson Amendments Act of 1988 (PAAA), which required DOE to enforce compliance with its nuclear safety requirements. Nuclear safety rules covering quality assurance and radiological protection of workers have been issued by DOE and implemented by contractors. From mid to late 1995, DOE completed development of its infrastructure to support the enforcement

2 The PAAA statute prevents imposition of civil penalties in matters involving certain named not-forprofit laboratories. 


\section{HIGHLIGHTS}

program, including: staffing a headquarters enforcement group of technical, investigative and legal enforcement professionals; developing a network of Field and Program Office coordinators to work with the headquarters' EH-Enforcement staff; issuing guidelines to support the enforcement investigation and enforcement action processes; implementing a noncompliance tracking system for contractor self-reporting of noncompliances; and training of coordinators.

Since becoming operational about one year ago, the DOE Noncompliance Tracking System (NTS) has received over 100 reports from contractors of noncompliances that are potentially more significant. Noncompliances that are below the NTS reporting threshold recommended by DOE are tracked by contractors in their own internal systems, and number in the hundreds. Additionally, DOE through its coordinators and independent reviews has identified about another 130 noncompliances that have not been reported by contractors. Of these over 200 cases, many have been closed by DOE on the basis of timely and appropriate initiative on the part of the contractor, or conclusions by DOE of low safety significance. Enforcement actions have been taken for several cases, with 7 Notices of Violation (NOV), 4 of which have had civil penalties imposed. These cases generally involved significant or potentially significant consequences to workers or the public, coupled with inadequate action or failure on the part of the contractor to take action until prompted by DOE. The civil penalties issued have ranged from $\$ 5,000$ to $\$ 75,000$ per case, all of which were paid by the contractors without being contested. ${ }^{3}$ Twelve (12) cases have been resolved using a formal Enforcement Letter to communicate DOE expectations, but with no NOV or civil penalty. Several other cases are pending.

DOE is planning some changes to the program based on lessons-learned, including the following: revising the Enforcement Policy to assure a proper balance of worker safety issues with issues of safety of the public from a major accident or release; refining the NTS reporting threshold; developing more uniform support to the program and consistent decision-making for noncompliance and enforcement issues across all Field Offices; and focusing special attention on those contractors that do not appear to be demonstrating initiative in selfidentifying and reporting noncompliances.
3 Civil penalties imposed on contractors may not be passed on to DOE; they are thus direct charges against a contractor's profits on a project. 


\section{ENFORCEMENT PROGRAM OVERVIEW}

This section is intended to provide an overview of DOE's enforcement program, for those who may not be familiar with the program.

Application of the program to specific cases in 1996 is described in subsequent sections.

\section{Background}

DOE has established a mechanism to penalize a

DOE contractor for unsafe actions or conditions that violate nuclear safety requirements for protecting workers and the public. It provides positive incentives for contractors to strive for an enhanced nuclear safety culture through attention to compliance to standards and requirements, self-identification of problems, reporting noncompliances to DOE, and initiating timely and effective corrective actions. PriceAnderson Amendments Act (PAAA) enforcement is part of DOE's overall Safety Management Program, which focuses on line management responsibility for safety, comprehensive requirements, competence commensurate with responsibilities, independent oversight, and enforcement. ${ }^{4}$

The 1988 Price-Anderson Amendments $\mathrm{Act}^{5}$ extended indemnification to DOE operating contractors for consequences of a nuclear incident. At the same time, Congress required DOE to begin undertaking enforcement actions against those contractors who violate nuclear safety rules. Although certain DOE facilities have been mandated in recent years to come under regulatory jurisdiction of the Nuclear Regulatory Commission, most DOE nuclear activities are exempt from such external regulatory oversight. The PAAA, in effect, required DOE to establish an internal selfregulatory process.

4 Safety Management Principles from October 1994 DOE letter to the DNFSB.

542 U.S.C. $2282 \mathrm{a}$.
DOE's regulatory basis for its enforcement program is published in 10 CFR Part 820 , Procedural Rules for DOE Nuclear Activities. Enforcement actions may include the issuance of Notices of Violations and, where appropriate, civil monetary penalties of up to $\$ 100,000$ per violation per day.

Such enforcement actions require the formal promulgation of rules in accordance with the Administrative Procedure Act, including adequate procedures for public notice and comment. To date, two substantive rules have become enforceable as final rules -- Quality Assurance Requirements and Radiation Protection for Workers ${ }^{6}$. Additionally, DOE rules on Contractor Employee Protection and Accuracy of Information (Submitted to DOE) ${ }^{7}$ have been identified as nuclear safety rules that are also enforceable. In October 1995, the Department completed putting in place the organizational infrastructure, training and formal guidance $^{8}$ needed to implement the enforcement program.

\section{Administration}

The DOE enforcement program is administered by a relatively small DOE Headquarters' $E H$ Enforcement staff, linked with PAAA Coordinators in Field and Program Offices, and supported by technical experts from DOE Headquarters and field elements. It is structured

6 10 CFR Part 830.120 and 10 CFR Part 835, respectively.

710 CFR Part 708 and 10 CFR Part 820.11, respectively.

8 - DOE-HDBK-1087-1995, Enforcement Handbook - DOE-HDBK-1089-1995, Identifying, Reporting and Tracking Nuclear Safety Noncompliances - DOE-HDBK-1085-1995, DOE Roles and Responsibilities 
to use existing resources, in conjunction with independent judgments by EH-Enforcement on compliance, safety significance, corrective actions and enforcement action.

The EH-Enforcement staff includes the Director and four full time enforcement personnel, a docketing clerk and administrative assistant, with two contractor full time equivalents, and assistance from over 50 Field and Program Office coordinators and numerous other DOE technical specialists.

\section{Noncompliance Identification and Reporting}

DOE expects contractors to implement appropriate steps to assure their activities comply with nuclear safety requirements, and to self-identify noncompliances. Minor or lesssignificant noncompliances may be tracked and closed out using a contractor's internal tracking system. These are subject to periodic review and audit by Field Office coordinator personnel. DOE expects that noncompliances above DOE's reporting thresholds for potentially more significant noncompliances will be reported into the Noncompliance Tracking System.

Additionally, noncompliances may be identified independently through DOE-Field Office input, Headquarters' reviews, DOE facility representatives, the Defense Board (DNFSB), DOE PAAA Coordinators, DOE Oversight, or reviews by $\mathrm{EH}$-Enforcement staff of various sources. Workers with noncompliance issues may also directly contact EH-Enforcement confidentially, or the site DOE PAAA Coordinator, the Nuclear Safety Hot-Line ${ }^{9}$, or the DOE Office of Contractor Employee Protection.

9 1-800-626-6376
EH-Enforcement, with input from Field and Program Office Management, will decide which noncompliances have the requisite level of safety significance such that an investigation should be conducted with the potential for enforcement action. This determination is made in accordance with threshold criteria described in DOE's Enforcement Policy ${ }^{10}$ and implementing guidance. Most cases are closed at this stage without an investigation, based on positive contractor initiative or low safety significance.

If an investigation is performed, it involves review of documentation from the contractor, assistance from Field personnel, and, in some cases, an onsite visit of several days to gather facts and circumstances on the noncompliance, conduct confidential interviews, and understand contractor actions in response to the noncompliance. Results of the investigation are documented in an Investigation Summary report.

Enforcement Decisions

The primary consideration in determining whether to take an enforcement action is the actual or potential safety significance of a violation, coupled with a determination of how aggressively the contractor identified, reported and corrected the problem. The potential for such mitigation of enforcement actions in particular cases provides a positive incentive for contractors to implement the desired safety culture.

EH-Enforcement works closely with Field and Program Office Management in making decisions on what enforcement actions are appropriate, based on the findings of the investigation. If necessary, an informal enforcement conference is held with senior

\footnotetext{
10 Appendix A to 10 CFR Part 820, General Statement of Enforcement Policy
} 
contractor management, and DOE Field and Program Office Management, to review the circumstances of the noncompliance, mitigating factors, and timeliness and adequacy of corrective actions. DOE also classifies the violation as Severity Level I (most significant, with actual or potential significant consequences to workers or the public), II, or III (greater than minor significance and important to avoid a more significant condition), based on an assessment of the unique facts of each case.

\section{Enforcement Process}

DOE's process and regulatory authority for enforcement actions are embodied in a Regulation (10 CFR Part 820), supplemented by the Enforcement Policy (Appendix A to 10 CFR Part 820) and guidance documents. Following an investigation and, if required, the informal enforcement conference, DOE's selection of an enforcement action can include any of the following, based on the facts and significance of the noncompliance:

(1) An enforcement letter, indicating that the investigation is being closed without further action, based on the proper actions having been taken by the contractor, but expressing DOE's related concerns or other views.

(2) A Notice of Violation with no civil penalty.

(3) A Notice of Violation with civil penalty.

(4) A Compliance Order.

(5) Referral to the Department of Justice for criminal prosecution.

Decisions on severity level, appropriate enforcement action, and magnitude of any civil penalty will be dependent on safety significance, initiative by the contractor in identification and reporting, and timeliness and effectiveness of corrective actions. With these elements appropriately addressed by the contractor, the Department can waive all or part of the civil penalties, and in some cases, refrain from actions entirely. Civil penalties are limited by statute to a maximum of $\$ 100,000$ per violation per day. DOE has established a scale of base civil penalties depending on the severity level of the violation and the type facility involved. DOE is planning a change to the Enforcement Policy to restructure the scale for base civil penalties as described in Section VI.

The PAAA statute provides exemption of DOE not-for-profit entities for any liability for civil penalties; however, DOE may impose Notices of Violation for these contractors: Additionally, other activities excluded by statute from DOE's nuclear safety requirements, and thus any enforcement action by DOE, include activities: regulated by the Nuclear Regulatory Commission; under the authority of the Director, Naval Nuclear Propulsion Program; or, conducted under the Nuclear Explosives and Weapons Safety Program.

In response to a Notice of Violation under the PAAA, contractors are required to document specific actions taken and planned to prevent recurrence of similar events. The contractor also either accepts the citation and pays any civil penalty, or denies the violation and seeks redress through an escalating series of steps, such as direct communication with EH-Enforcement providing the basis for the contractor's position, appeal to the Secretary of Energy, or request for an on-the-record adjudication before an Administrative Law Judge. Settlement can occur at any point in the process.

The contractor's commitments on corrective actions and schedules for completion become part of the enforcement proceeding record. Field Office personnel verify completion of corrective actions before a case is closed. 


\section{ENFORCEMENT PROGRAM OVERVIEW}

Information on a particular enforcement proceeding is available to the public, once $\mathrm{DOE}$ moves to the stage of a preliminary notice of violation (PNOV); prior to that point the matter is in the investigative phase and is considered pre-decisional. Records are maintained by the Docket Clerk at DOE headquarters. ${ }^{11}$ At any time workers or members of the general public may request EH-Enforcement to review an alleged violation. A DOE Hot Line that communicates directly with EH-Enforcement has been made available and is discussed further in Section III.

DOE's approach to enforcement involves some relatively innovative methods to avoid manpower intensive inspection forces and better motivate contractor ownership of compliance and safety. This is expected to result in a more effective and efficient regulatory process that, in conjunction with other elements of the DOE Safety Management Program, improves safety of the public and workers for DOE activities.

Further guidance on DOE's PAAA enforcement process may be found in DOE-HDBK-1087-95, Enforcement Handbook, as well as 10 CFR Part 820, Procedural Rules for DOE Nuclear Activities (Subpart B), and its Appendix A, General Statement of Enforcement Policy.

11 Office of the Docket Clerk, EH-10, 100 CXXI, 19901 Germantown Road, Germantown, MD 20874, (301) $903-$ 0112. 


\section{ACCOMPLISHMENTS}

\section{INFRASTRUCTURE DEVELOPMENT}

Compliance with the radiological protection rule (10 CFR Part 835) was required by January 1, 1996. Contractor actions to come into compliance with the Quality Assurance rule also occured by late 1995. Accordingly, DOE focused in mid to late 1995 on completing the infrastructure development of the enforcement program. This included an array of support organization development (contractor, DOE Field and Program Office coordinators), establishing noncompliance reporting systems, issuance of guidance documents, conduct of training, and dissemination of information. The intent was to complete development of these to be in a position to commence enforcement investigations of noncompliances in early 1996. This was achieved. The following were the major enforcement program infrastructure development activities accomplished in mid to late 1995.

\section{DOE and Contractor Coordinators}

A key element of the organizational infrastructure is the PAAA Coordinators network. This network was designed to establish the communications link between DOE line organizations, contractors and $\mathrm{EH}$ Enforcement, to ensure that effective organizational arrangements are in place to identify and resolve PAAA issues, and to draw support from existing qualified personnel within other DOE organizations. Membership in the network includes contractor, DOE Field Office and DOE Program Office personnel selected by their management.

Since the primary responsibility for identifying and correcting noncompliances rests with DOE's contractors, the position of Contractor PAAA Coordinator was established to assist his/her management in reviewing issues to detect potential PAAA implications and to notify DOE of noncompliances. EH-Enforcement and Field Office Coordinators interact with these Contractor Coordinators to obtain preliminary information about noncompliances and the actions planned to correct them.

DOE PAAA Field Office Coordinators are the primary contacts for EH-Enforcement and contractor personnel. These Coordinators provide assistance to EH-Enforcement staff during the evaluation of noncompliances and technical support during enforcement investigations. Similarly, EH-Enforcement draws upon support from $D O E$ Program Office $P A A A$ Coordinators having program or facility specific expertise during the evaluation, investigation and decision making process. Activities typically performed by the DOE Field Office and Program Office PAAA Coordinators include:

1. Monitoring contractor reports, facility representative reports, and other sources of contractor performance to independently identify noncompliances.

2. Obtaining information and collaborating with EH-Enforcement staff to evaluate the safety significance and facts of noncompliances.

3. Directly participating in investigations and coordinating identification of other local DOE technical support personnel when necessary to support enforcement reviews.

4. Providing status of corrective actions by contractors and confirmation of closure for safety significant noncompliances.

5. Coordinating the periodic evaluation of noncompliances below the reporting threshold and tracked locally by the contractor. 


\section{ACCOMPLISHMENTS}

Nuclear Safety Noncompliance Information System

By May 31, 1995, EH-Enforcement completed the nuclear safety noncompliance reporting process. The process consists of two components: the DOE-wide Noncompliance Tracking System (NTS); and the contractors' self-tracking systems. The proper use of these components by contractors reflects conformance with DOE's philosophy of encouraging effective and prompt self-identification and reporting.

The NTS is a centralized database that allows contractors to provide information to the DOE complex about potentially more safetysignificant noncompliances. DOE has established discrete thresholds for those noncompliances it expects to be reported to DOE via NTS. Each record in the database includes a text description of the occurrence or condition, the corrective actions implemented to correct it and prevent recurrence, and other pertinent data points. The database was designed so that a record cannot be closed until all corrective actions are shown to be completed. Guidance for the contractors to use in deciding which issues should be reported into this system is contained in DOE Handbook 1089-95.

The second component includes contractors' self-tracking systems. These systems track noncompliances that are below the threshold for reporting into the NTS. Issues reported into the self-tracking systems are subject to review by DOE and should be periodically reviewed by the contractor to identify trends.

It is of particular importance that the NTS and the related Handbook were developed using input from a group of contractor volunteers to assure establishment of a practical reporting process and threshold. This group worked with EH-Enforcement on issues relating to the identification and reporting process, reporting thresholds and substance of reports. The Office of Enforcement acknowledges the useful contributions of this group.

Use of the NTS is addressed in Section III.2 below.

\section{Guidance Documents Issued}

EH-Enforcement issued three guidance documents to assist contractors and DOE personnel in understanding expectations in the enforcement process. Each was written to provide comprehensive information about a specific aspect of the Enforcement Program. The following is a description of the guidance documents.

1. DOE Enforcement Program Roles and Responsibilities Guidance Handbook (DOEHDBK-1085-95) identifies areas of interface between the EH-Enforcement and other DOE entities and the notification protocols.

2. The Enforcement Handbook (DOE-HDBK1087-95) provides details on the procedural and deliberative processes used by DOE in carrying out its enforcement responsibilities. It is a handy source of fundamental information about the Enforcement Policy and process.

3. The Guidance for Identifying, Reporting and Tracking Nuclear Safety Noncompliances (DOE-HDBK-1089-95) provides contractors with information about DOE's philosophy for identifying, reporting, and correcting nuclear safety noncompliances. It provides discrete thresholds for those noncompliances to be reported into NTS, and includes examples of noncompliances to provide a practical reference guide. 


\section{ACCOMPLISHMENTS}

\section{Training}

During 1995 and 1996, EH-Enforcement took steps to ensure that the DOE and Contractor community understood the DOE Enforcement Program and enforcement related initiatives, DOE's expectations of contractors, and responsibilities to establish their own PAAA compliance programs. These steps included onsite contractor briefing, formal workshops for DOE and Contractor PAAA Coordinators, and on-the-job training to interested DOE PAAA Coordinators. The on-the-job training to DOE PAAA Coordinators included their involvement in the entire enforcement investigative and resolution process, including participation at enforcement conferences. This training was provided by EH-Enforcement and enabled participants to enhance their knowledge without incurring tuition costs.

\section{Nuclear Safety Hotline}

EH-Enforcement maintains a toll-free hotline to provide a direct means for contractor employees to confidentially report potential violations of nuclear safety rules. The hotline underscores the philosophy of DOE to encourage communication about noncompliances. Callers wanting to talk to an enforcement specialist may telephone the hotline at 1-800-626-6376 during business hours. EH-Enforcement provides an answering machine to receive calls after hours.

\section{Information Dissemination}

DOE makes use of several paths to communicate information on the enforcement program and specific enforcement actions. EH-Enforcement uses the Operating Experience Weekly Summary (OEWS) to communicate information to $\mathrm{DOE}$ and contractors about enforcement issues. The Summary is a DOE publication that is distributed across the DOE complex to contractors and
DOE personnel. For example, this publication is used to provide information about particular Notices of Violation issued by DOE, as well as to share information about exemplary cases where a Notice of Violation was not issued because the noncompliance was promptly identified, reported and corrected by the contractor. In addition, the Summary is used to communicate answers to questions of a general nature about the application of the enforcement policy.

Information relating to the Enforcement Program and enforcement actions is made available to the public and the DOE community. This information can be obtained by visiting the DOE Public Reading Room, or by accessing the EH-Enforcement Home Page ${ }^{12}$ through the Internet. Further, DOE uses press releases to inform the public about newsworthy enforcement events.

\section{NONCOMPLIANCES, INVESTIGATIONS AND ENFORCEMENT ACTIONS}

\section{Cases Considered}

DOE considers for investigation a variety of information sources of noncompliances, including the NTS reports by contractors, and other cases of noncompliance identified by $\mathrm{DOE}$. During this reporting period, EH-Enforcement reviewed over 200 noncompliance issues for nuclear safety rule applicability and potential formal enforcement investigation.

As of December 31, 1996102 noncompliance reports have been filed into NTS. Of these cases, DOE was able to complete an initial

12 Enforcement and Investigation Home Page, Internet address: http://tis-nt.eh.doe.gov/enforce/ 


\section{ACCOMPLISHMENTS}

DOE identified over 130 other noncompliance cases, through review of the Occurrence Reporting System (ORPS), DOE facility representative reports, Defense Nuclear Safety Board (DNFSB) trip reports, and other sources of contractor noncompliances. Of these other DOE identified noncompliances, DOE conducted a substantive review of 51 , and closed most of these without an investigation or enforcement action. Figure III-1 illustrates the sources for identification of the potentially more significant noncompliances, whether identified by DOE or the contractor, and the relative number of each.

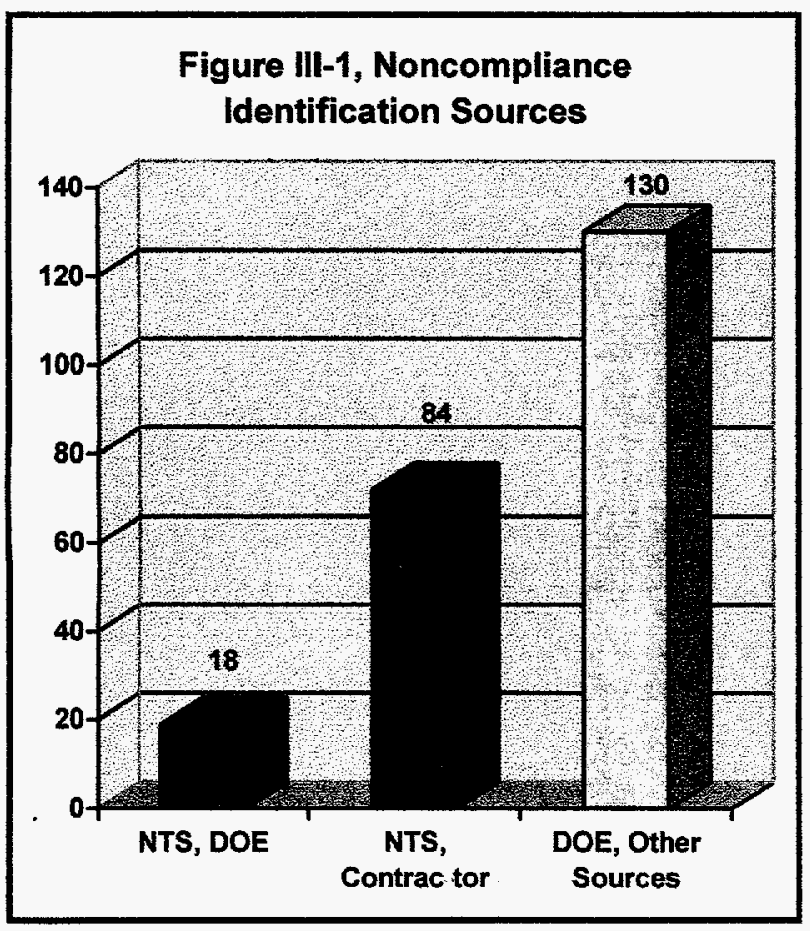

DOE's reviews of these noncompliance reports focused on the safety significance of the issues, as well as the degree to which the contractor was demonstrating the desired behavior of aggressive self-identification, reporting and corrective action. Where DOE was not satisfied that appropriate actions had been taken and that the safety significance warranted further investigation, DOE undertook a more comprehensive review.

\section{Investigations/Reviews \\ With No Enforcement Action}

DOE conducted many comprehensive reviews of noncompliance cases. In some of these cases it was found that the contractor had properly self-identified and reported the problem, and was taking the appropriate action. These cases were often closed by making appropriate annotation in the NTS system, including relying on observations and conclusions of the Field Office coordinator and documented in NTS. In some cases DOE found it appropriate to issue a letter to the contractor as part of the close-out of the case to clarify a DOE position or to communicate DOE expectations to further enhance resolution of the issue. Where such a letter was issued, this was referred to as an Enforcement Letter, however no additional enforcement action was taken and the letter typically incorporated Field and Program Office input. DOE issued 12 Enforcement Letters in 1996 to formally close out investigations.

\section{Notices of Violation and Civil Penalties}

In those few cases where DOE determined that the circumstances of the case and the actual or potential safety consequences were sufficiently serious, a formal enforcement action was taken. The purposes of the actions were multiple, and included: clearly note violations of DOE nuclear safety requirements and the potential safety consequences of such actions by contractors; more clearly communicate DOE's expectations of contractors and the need to substantially change behavior and practices; and, emphasize the need for contractors to aggressively focus on a conscientious safety culture that self-identifies noncompliances, reports these to $\mathrm{DOE}$, and takes prompt and effective corrective actions. 


\section{ACCOMPLISHMENTS}

In 1996 DOE issued seven (7) Preliminary Notices of Violation (PNOV), each to a separate contractor, with four civil penalties totaling $\$ 117,500$. Each PNOV typically included several related violations, and rolled these together into a single violation. In one case the contractors were cited for two separate violations, with all of the individual noncompliances associated with each of two events rolled-up into a single violation.

In the four cases for which civil penalties were imposed, all four contractors paid the full penalty. Three PNOV's had no civil penalty attached, since the contractors involved were not-for-profit laboratories or one of their subcontractors, and these are specifically excluded from application of civil penalties under the statutory provisions of the PAAA of 1988. Figure III-2 summarizes the enforcement actions or outcomes for the various cases considered and resolved by DOE in 1996. These cases derived from NTS reports and other sources of noncompliances identified by DOE, where DOE judged that potential safety significance warranted a substantive review.
Most cases were closed without enforcement action based on proper initiative by the contractor or conclusions of low safety significance once the facts of the case were reviewed. Sections IV and V provide examples of selected Office of Investigation and Enforcement cases in 1996.

Figure III-2

DOE Actions for 1996 Cases

(for Cases Resolved in 1996)

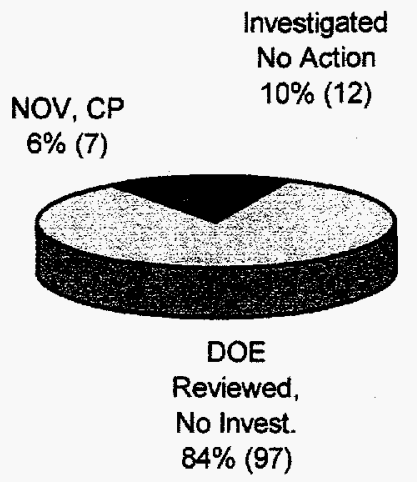




\section{Radiological Control Program Violations at Rocky Flats}

On October 7, 1996, DOE issued Preliminary Notices of Violation and proposed civil penalties of $\$ 37,500$ each against Kaiser-Hill Company, the integrating contractor at the Rocky Flats Environmental Technology Site, and the Safe Sites of Colorado Company, a subcontractor to Kaiser-Hill. DOE took enforcement action against these companies because of radiological deficiencies (violations of 10 CFR Part 835) and work control deficiencies (violations of 10 CFR Part 830.120) associated with two incidents that took place at the Rocky Flats site on March 4 and April 18, 1996. The integrating contractor was cited because it had overall responsibility for the Rocky Flats radiation protection program. DOE cited the subcontractor because it was responsible for safe operation of the facilities where the violations occurred including implementation of the radiological protection program. This action $(\$ 75,000$ total civil penalty) was unprecedented because it was the first time that DOE proposed civil penalties against both the integrating and subcontractor companies.

On March 4, two process operators were venting 12 waste drums containing solidified sludge when a release of contaminated material, including plutonium-239 occurred. The radiological control technician in the area could not determine the magnitude of the release because radiation monitoring instrumentation read off-scale high. Since his instrument scale read as high as 1 million $\mathrm{dpm} / \mathrm{cm}^{2}$, the contamination was greater than this, but unknown specifically. Contrary to procedure and radiation work permit requirements, facility managers allowed the process operators to decontaminate and then continue their work assignments. Radiation technicians did not monitor the atmosphere for airborne contamination or provide operators with increased protective clothing. As a result, the two operators and others nearby worked in conditions that were more hazardous than allowed by contractor radiation work permit requirements.

On April 18, five process specialists were contaminated when a bag containing plutoniumcontaminated waste was breached. The specialists had put the waste in plastic bags. They were gram estimating the plutonium in the bags and placing the bags into drums. Against procedure and radiation work permit requirements, the specialists removed their respirators after bagging the waste, but before completing the disposal of the bags. Also contrary to procedure, the radiological control technician was absent for completion of the work. All five specialists were contaminated on their protective clothing and received confirmed plutonium uptakes, with one as high as $8 \%$ of the DOE annual dose limit.

In letters to the two companies, DOE stated that it was concerned with radiological work control and that the civil penalties were imposed to ensure that work control problems are promptly identified and corrected. Each company accepted the Preliminary Notice of Violation and paid the assessed penalty.

The primary considerations for determining whether DOE takes enforcement action are the actual or potential safety significance of the violation, coupled with how quickly the contractor acts to identify and correct the problem. In this case the noncompliances associated with the March 4, 1996 incident were identified by DOE and not the contractor, and there had been a history of numerous radiological protection program violations identified by DOE without adequate corrective actions to preclude a potentially more serious 


\section{SUMMARY OF SIGNIFICANT ENFORCEMENT ACTIONS}

event such as the two that occurred. DOE thus concluded that the contractor had not properly and promptly self-identified these noncompliance problems, had not self-reported them prior to some self-disclosing event, and had not effected prompt corrective actions to preclude recurrence. Accordingly, DOE did not mitigate from the base civil penalties stated in DOE's Enforcement Policy, and issued a PNOV to each company citing Severity Level II violations for each of the two incidents.

\section{Extremity Radiation Dose at Hanford}

On July 18, 1996, DOE cited Westinghouse Hanford Company of Richland, Washington with violating nuclear safety rules and issued a $\$ 37,500$ penalty. This action resulted from a February 13, 1996 incident at the Hanford Tank Farms where a pipe-fitter received nearly 13 rem radiation exposure to his forearm and hands. The pipe-fitter received the exposure during removal of a contaminated temperaturemeasuring device from a high-level radioactive waste storage tank.

A work crew had installed a flexible receiver to wash and bag the temperature-measuring device as it was withdrawn from the tank. The purpose of the flexible receiver was to minimize radiation exposure and contamination. As the operators retracted the temperature-measuring device, the tank riser became plugged with sludge which prevented wash water from draining back into the tank. As a result, wash water backed up into the flexible receiver, causing water to leak. Contamination from the water exceeded the Radiation Work Permit limits, prompting the radiological control technicians to implement emergency spill cleanup procedures. An operator attempted to unclog the receiver by lowering the thermocouple into the tank; however, it jammed. The radiological control technician and a pipe-fitter climbed onto the receiver platform. The pipe-fitter shook the bagged temperature-measuring device in an attempt to release the plug. The technician monitored the radiation levels and became confused between the readings of his hand-held monitor and personal alarm dose equipment. Neither the pipe-fitter nor the technician cleared the receiver platform even though the survey instrument showed an off-scale reading over 5 $\mathrm{Rad} /$ hour. When the pipe-fitter left the work area and read his pocket dosimeter, it indicated off-scale high.

DOE transmitted the Preliminary Notice of Violation to Westinghouse Hanford Company by letter. The letter stated that the company had not properly anticipated or planned for radiological conditions and hazards. Westinghouse accepted the Preliminary Notice of Violation and paid the full civil penalty.

\section{Operating With Disabled Criticality Safe Tank at PNNL}

On April 3, 1996, DOE cited Pacific Northwest National Laboratory (PNNL), because it failed to properly respond to a high-level alarm condition in the criticality safe slab-tank. The alarm, which was part of a safety feature designed to prevent unplanned nuclear criticality at the Applied Chemistry Laboratory, remained in a high-level alarm condition from March through October 1995.

$\mathrm{EH}$-Enforcement began inquiries into this issue in November 1995, after it received a report identifying several potentially significant occurrences at the Applied Chemistry Laboratory. In January 1996, EH-Enforcement personnel conducted an on-site evaluation and concluded that violations of work processes and quality improvement provisions of the Quality 
Assurance Rule (10 CFR Part 830.120) had occurred.

During their evaluation, EH-Enforcement personnel learned that neither the building managers nor the operations staff understood that the tank was an engineered safety feature. Also, these personnel did not understand that the operators were required to drain the tank at regular intervals and upon receipt of a high-level alarm. Processes were not in place to recognize the alarm condition as a safety problem. As a result, the contractor did not take timely action to determine the safety significance of the alarm and effect corrective actions.

EH-Enforcement and local DOE officials were concerned with the history of extended delays in draining the slab tank. For example, prior to the committed implementation date of the Quality Assurance rule, there had been a 15 -month delay between the time the control room received a high-level alarm for the tank and the time it was emptied. Such long delays in draining the tank, coupled with the repetitive nature of the problem, would normally warrant a Severity Level II classification of the violations. However, DOE mitigated the classification to Severity Level III, because once the matter was elevated to senior management, the contractor acted appropriately to understand and correct the problem. No civil penalty was assessed since PNNL is exempt from imposition of civil penalties under PAAA statute. A PNOV was issued by DOE and accepted by PNNL.

\section{Uncontrolled Radiation Field at Sandia National Lab}

On August 14, 1996, DOE issued a Preliminary Notice of Violation (PNOV) and proposed civil penalty of $\$ 5,000$ against the Sandia Corporation, Albuquerque, New Mexico, for violations of the Occupational Radiation
Protection Rule (10 CFR 835). The violations occurred in February 1996 during field radiography operations in the Liquid Metal Processing Laboratory at Sandia National Laboratories. Sandia was cited for failure to control access and provide necessary radiation warnings to preclude inadvertent entry of personnel into radiation areas.

The potential existed for the creation of high and/or very high radiation areas during field radiography. Although doors to the Liquid Metal Processing Laboratory were locked, all building employees had keys. The radiographer was not aware of his responsibility to control access, nor were radiological control technicians aware that employees could unknowingly enter a radiation field during these operations.

In the transmittal letter to the contractor, DOE expressed concern that similar problems involving radiological work controls had not been corrected. For example, in July 1995, a Joint Investigative Team of contractor and DOE personnel identified significant radiological program deficiencies and concluded that nonadherence to operating procedures was so widespread that it had become institutionalized. In response to this finding, Sandia senior management formally committed to a series of corrective actions to resolve the problem. However, DOE learned during the enforcement conference that Sandia had not communicated the findings of the Joint Investigation Team to facility managers.

DOE classified the violations as Severity Level II because of the many past problems with the contractor in the area of radiological work control and failure to implement corrective actions. The contractor accepted the PNOV and paid the penalty. DOE Field Office and EHEnforcement personnel are monitoring completion of the corrective actions. 


\section{EXAMPLES WHERE ENFORCEMENT ACTION \\ WAS DEFERRED}

\section{Revamped Contamination Control Program at Mound}

On January 11, 1996, an inadvertent transfer of radiological material at a Mound, Ohio, facility contaminated individuals, equipment, and locations outside radiological areas. Although exposures to personnel were low, EG\&G Mound Applied Technologies (EG\&G), the contractor, determined that procedural breakdowns and deficiencies led to the incident and reported it into the NTS within two weeks of the event.

The deficiencies that the contractor reported to DOE included vague Radiation Work Permits, inconsistent radiological postings, failure to adequately address radiological aspects in prejob briefings, inadequate attention to the expiration of Radiation Work Permits, and inadequate control of material being surveyed before its release to uncontrolled areas. EG\&G promptly implemented corrective actions to resolve these programmatic deficiencies.

Contractor management also determined that the incident, in combination with other contemporaneous radiological incidents indicated a broader problem with the overall contamination control program. In response to this determination, EG\&G established a Contamination Control Review Team composed of EG\&G senior personnel and managers, union representatives, DOE-assistance personnel and outside independent experts. This team investigated incidents from January 1995 thorough January 1996 involving radiological program controls, contamination of personnel and the spread of contamination. The team identified a comprehensive set of programmatic weaknesses and recommended 58 corrective actions. All corrective actions have been implemented.

EH-Enforcement staff conducted an evaluation of the adequacy of and progress toward completion of corrective actions related to the January 11 event, and reviewed the report prepared by the Contamination Control Review Team. EH-Enforcement staff determined that the contractor had performed a comprehensive root cause analysis that included a review of other contamination events, and concluded that the corrective actions taken by the contractor to prevent recurrence were thorough and timely completed. Additionally, performance indicators showed a dramatic decrease in contamination occurrences and noncompliances with radiological control requirements in the months following completion of both the short term and longer term corrective actions. Since the actions taken by the contractor reflected proactive initiatives and prompt action to identify, report and correct the noncompliance, enforcement sanctions were completely mitigated.

\section{Improved Work Controls at Westinghouse-Hanford}

In May 1995, the Westinghouse Hanford Corporation, Hanford, Washington, identified and subsequently reported to DOE noncompliances with the requirements of the Quality Assurance Rule (10 CFR 830.120). The noncompliances occurred at the B-Plant/Waste Encapsulation and Storage Facility and were identified by the contractor during a comprehensive self assessment of the Operational Safety Requirements program.

The self-assessment was initiated by the facility director after two events led him to conclude 


\section{EXAMPLES WHERE ENFORCEMENT ACTION WAS DEFERRED}

that the Operational Safety Requirements program at this facility was potentially not being properly implemented. This assessment included an evaluation of existing Operational Safety Requirements, controlled plant documents, plant conditions and record keeping practices. It found among other things that current, controlled Operational Safety Requirements were not being effectively used to identify limiting plant conditions or to verify surveillance and plant configuration requirements. $\mathrm{EH}-$ Enforcement evaluated the findings and conclusions of the contractor self-assessment and agreed with the contractor's finding that noncompliances with the Quality Assurance Rule (10 CFR 830.120) likely occurred.

The contractor also developed comprehensive corrective actions. In this case DOE exercised its discretion not to undertake a formal enforcement action. This decision was reached because the contractor took initiative to identify and report the noncompliances and implemented appropriate and timely corrective actions. DOE issued an Enforcement Letter in September 1995 to communicate its decision and the basis for no enforcement action, and confirmed completion of corrective actions before closing this case.

\section{Improving Compliance With Radiological Postings at Brookhaven National Lab}

In May 1996, Brookhaven National Laboratory, Upton, New York, reported noncompliances with requirements of the Occupational Radiation Protection Rule (10 CFR 835). The noncompliances involved four instances of contractor or subcontractor failure to comply with area radiological warning signs. The noncompliances were identified by Brookhaven field staff at the time of occurrence.

Brookhaven management appropriately viewed the incidents as a programmatic failure and responded accordingly. It launched a laboratory-wide initiative for oversight and supervision of contractor personnel in its corrective action plan. Short range, interim solutions as well as long-term solutions for control of contractor-related radiological safety issues site-wide were addressed by a high level management task force appointed for this purpose. The short term corrective actions included: 1) refresher training in radiation protection for engineers, designers and field personnel who supervise contractors and subcontractors; 2) a meeting for Brookhaven construction contractors that included coverage of radiological protection rule (10 CFR 835) requirements; 3 ) revised lesson plans for contractor orientation training to include more detailed instruction regarding radiological posting; and 4) development of a policy on how construction in radiological areas will be managed.

DOE also recognized that Brookhaven field staff interceded when subcontractor personnel failed to follow established requirements, and Brookhaven management took aggressive corrective actions. These corrective actions, when fully implemented, in addition to selfidentification of the noncompliances, satisfy the discretionary criteria described in DOE's nuclear safety enforcement policy. As a result, DOE exercised its discretion not to take enforcement action, contingent upon full implementation of the proposed corrective actions. DOE Field Office and Enforcement personnel are monitoring completion of these corrective actions. 


\section{EXAMPLES WHERE ENFORCEMENT ACTION WAS DEFERRED}

DOE did conclude, however, that subcontractor actions were not appropriate, including failure to identify the noncompliance or properly respond when subcontractor management became aware of the noncompliance. Accordingly DOE took action through issuance of a PNOV (Preliminary
Notice of Violation) against the subcontractor. No civil penalty was considered since subcontractors and suppliers of specifically named not-for-profit Laboratories are exempted by the PAAA statute, as are the Laboratories themselves, from imposition of civil penalties. 
Since the Enforcement Program has now been functional for about one year, and a number of enforcement actions have been taken, some lessons learned from this time period can be observed. Addressing these now can lead to the continued improvement of the program. The following changes and improvements in the enforcement program are planned for 1997.

\section{Enforcement Policy Revision}

DOE intends to revise its General Statement of Enforcement Policy, which has been published as Appendix A to 10 CFR Part 820, Procedural Rules for DOE Nuclear Activities. DOE's Enforcement Policy provides the bases and processes used for various enforcement actions that may be taken by DOE for violations of its nuclear safety requirements.

The Enforcement Policy was originally issued in August 1993. Since then DOE has had experience in application of the Policy, and the complexion of DOE's operating facilities has changed from a large array of weapons production facilities, to a broad mix of operating facilities, decontamination and decommissioning operations, and waste processing activities. Based on this experience with the Policy and the changing mission of DOE, it was found that inadequate emphasis was placed on worker radiological safety issues. The planned revised Policy keeps much of the current structure of the process, but changes the formula for establishing base civil penalties, both simplifying the formula and establishing uniform emphasis based on safety significance, whether to individual workers or to the public. Base civil penalties would be tied to the Severity Level of the violation.
The planned revised Policy adds clarification to DOE considerations and expectations in its enforcement action deliberations, such as how self-disclosing events are treated, application of rules to nuclear safety activities - not just facilities, consideration of per-day provisions of base civil penalties, and DOE employee liability. Additionally, the planned Policy revision will address some elements of the Enforcement Process that are not well described in the current Policy, such as use of Enforcement Letters, conduct of enforcement investigations, and allowance of contractor self-tracking for noncompliances that are below a prescribed NTS reporting threshold. DOE expects to issue for public comment the planned revision to the Enforcement Policy, through publication in the Federal Register, by early 1997.

Although DOE does not intend to seek changes at this time, it is planning to study further the exemption on imposing civil penalties on for-profit subcontractors working for not-for-profit laboratories. Presently both the laboratories and any contractors or suppliers to the laboratories are exempted by the Price Anderson statute from imposition of civil penalties by DOE for violations of nuclear safety requirements. Any changes to this exemption would require legislation, rather than a change to the Enforcement Policy.

\section{NTS Reporting Thresholds}

DOE worked interactively with contractors in establishing the present NTS reporting thresholds in order to assure clarity and reasonableness in the defined thresholds. The intent was to avoid a large number of minor noncompliances having to be reported to DOE, but recognizing that what is reported may be of varying safety significance. DOE 


\section{CHANGES AND IMPROVEMENTS}

wanted to maintain discretion on which reported noncompliances were of such safety significance that DOE would choose to undertake a review or investigation. In some cases, DOE has undertaken an investigation where the noncompliance was below the threshold, but DOE judged that the incident involved a potential for more significant consequences.

Based on this experience in finding certain cases of potential significance that were below the reporting threshold, DOE has decided to undertake a reconsideration of the reporting threshold. The areas of particular concern are cases of personnel contamination, including multiple personnel contaminations or confirmed uptake that are classified by ORPS ${ }^{13}$ criteria as "off-normal" and thus below NTS reporting criteria, and cases of low personnel radiation exposure. Although the actual consequences in these cases may have been low, several involved situations where the consequences could have been substantially greater. Some of these involved cases where the substantially greater potential consequences were not limited by any particular management controls but were simply a matter of luck that the consequences were not greater.

DOE is looking at the NTS reporting thresholds for these areas, and considering changes to assure that other potentially significant cases not presently being reported are placed into NTS. The revised reporting thresholds will be: published in a revision to DOE's present guidance on NTS reporting

13 DOE's Occurrence Reporting and Processing System thresholds ${ }^{14}$, announced in the DOE Operating Experience Weekly Summary publication (OEWS), and communicated directly to identified DOE and contractor PAAA Coordinators.

\section{Consistent Field Office Involvement}

DOE's enforcement program is founded on an approach of making use of existing resources and programs, such as personnel in Field Offices. These personnel are integral to the enforcement program. They are aware of conditions that represent potentially significant noncompliances, most capable to judge the adequacy of corrective actions, and most efficient in confirming that corrective actions have been completed. The Office of Enforcement and Investigation has no direct authority over these Field Offices, and thus structured an arrangement that is based more on mutual consent rather than management authority to obtain the support and involvement of individual Field Offices. The program was established with individual coordinators being designated in each Field Office to be the point of contact for EHEnforcement on enforcement matters and for contractors on PAAA issues. Over the first year of implementing the enforcement program, substantial variation in program involvement among Field Offices has been experienced.

This variation among Field Offices appears to be one that relates to both differences in perceived role of the Field Office when

14 DOE-HDBK-1089-95, Guidance for Identifying, Reporting and Tracking Nuclear Safety Noncompliances, July 1995. 
interacting with the contractor on PAAA issues, and divergence among Field Office managers on extent of desired involvement in the enforcement program. These differing perceptions have manifested themselves in variations in the following types of enforcement program activities:

- Monitoring contractor activities to identify noncompliances. (Some Offices are very active in looking for such conditions among various contractor reports, DOE reviews, and occurrences at the facility, while others put forth little or no effort in this area.)

- Interactive dialogue with contractor on issues of compliance and reportability. (Some Offices establish an ongoing role for such questions while others leave this entirely to the contractor.)

- Taking positions on whether issues are noncompliances or reportable into NTS. (Some Offices feel this conflicts with "partnering" with the contractor and will not take a position, while others routinely formalize a position on such questions.) - Active support of enforcement and investigation activities. (Most Offices provide their coordinator and other resources expert in the area to assist EH-Enforcement investigation of compliance and safety significance. Some Offices provide little or no participation in such investigations or reviews.) - Providing input on adequacy and closure of corrective actions. (Most Offices provide input to assist the enforcement process; however, this support is mixed. Without support in this critical area, the limited manpower of EH-Enforcement must make cursory judgments on these questions.)

To improve this area DOE is undertaking several initiatives:

(1) A coordinator workshop with representatives from most Field and Program
Offices was conducted in December 1996. A focus of this workshop was lessons learned across the Complex in the first year of the enforcement program, sharing best practices and roles in different Field Office so these may be taken back to other Offices, and mutually establishing a definition of training requirements and roles for coordinators.

(2) Further planning sessions between senior EH management and individual Field Office management to better establish working relationships, understanding of roles, and strategies for focusing on particular contractor problem areas.

Table VI-1 illustrates the relative involvement of different Operations Offices for NTS reports where sufficient time has elapsed that Field Office input could be expected.

\section{Contractors With Less Initiative in Identification and Reporting}

Over the past year DOE has found some contractors to be less ambitious in identifying PAAA noncompliances and reporting these to DOE. In some cases these contractors identified more significant noncompliances but were reluctant to report these to DOE, and simply tracked these in their internal tracking system. Some others have not even focused on identifying the noncompliances and improving safety of their operations. In certain of these cases DOE has taken enforcement action, and through the enforcement action communicated to the contractor the desired safety awareness and compliance assurance desired by DOE as reflected in DOE's nuclear safety requirements.

For those contractors where DOE has taken enforcement action, DOE will continue to monitor the responsiveness of contractor 


\section{CHANGES AND IMPROVEMENTS}

initiative in identifying noncompliances, reporting issues above DOE's reporting threshold into NTS, and taking prompt and effective corrective actions. DOE's monitoring activities will include review of occurrence reports, routine contractor monitoring by Field Office personnel and communication with the EH-Enforcement staff, and consideration of Defense Board (DNFSB) reports, Office of Oversight findings, and worker input such as via the Hot-Line.

A number of other contractors have reported very few or no noncompliances into DOE's NTS system. For these contractors, DOE intends to focus special attention to determine if these contractors are demonstrating exemplary compliance and safety performance, or are avoiding their responsibility to aggressively identify noncompliances and focus on improving safety of operations. DOE will exercise similar monitoring activities as described above, but will also consider a special site-visit to the contractor's facility to review identified noncompliances and other records.
As a point of information, Table VI-2 summarizes the NTS report frequency by contractor as of December 31, 1996. The contractors listed in the Table are those that are direct management and operations (M\&O) contractors to DOE, responsible for nuclear facilities. Some of these manage large, complex sites with many nuclear facilities, while others manage smaller sites or sites with few nuclear facilities. Some of these are research laboratories where it may be reasonable that few or no NTS reports would appear; however; larger sites with many nuclear facilities or radiological hazards should be expected to have multiple NTS reports if the contractor is aggressively identifying, reporting and fixing its problems. Thus a relatively large number of NTS reports by a particular contractor may be indicative of positive contractor initiatives. Accordingly, a direct comparison across all contractors is not appropriate; but, the table does show the wide variation in use of NTS by contractors.

Contractors with low reporting into NTS for the type activities conducted should potentially receive special attention. 
Table VI-1

FIELD OFFICE INVOLVEMENT15

\begin{tabular}{|c|c|c|}
\hline Field Office & $\begin{array}{l}\text { No. of NTS Reports } \\
\text { Asserted By Contractor } \\
\text { To Be Completed }\end{array}$ & $\begin{array}{l}\% \text { Reports With } \\
\text { Field Office Comments } \\
\text { on Corrective Actions }\end{array}$ \\
\hline Albuquerque Operations Office & 6 & $33 \%$ \\
\hline Chicago Operations Office & $5^{16}$ & $60 \%$ \\
\hline Idaho Operations Office & 4 & $100 \%$ \\
\hline Nevada Operations Office & 0 & N/A \\
\hline Oak Ridge Operations Office & 2 & $100 \%$ \\
\hline Oakland Operations Office & 2 & $50 \%$ \\
\hline Ohio Operations Office & 4 & $50 \%$ \\
\hline Richland Operations Office & 11 & $91 \%$ \\
\hline Rocky Flats Field Office & 3 & $100 \%$ \\
\hline Savannah River Operations Office & 6 & $100 \%$ \\
\hline
\end{tabular}

15 Based on NTS Reports where the contractor has indicated that all corrective actions have been completed by October 31, 1996, thus allowing sufficient time for Field Office involvement to confirm completion of corrective actions. Filed Office involvement was recognized where comments have been provided by the Field Office either into NTS or via formal correspondence to the EH-Enforcement. In a few cases, such as for the Richland Operations Office, ongoing review of corrective actions and dialogue with EH-Enforcement is still occurring for some of these cases.

16 This Office is deferring comment on one NTS report pending response and resolution to an Enforcement Letter. 


\section{CHANGES AND IMPROVEMENTS}

Table VI-2 - CONTRACTOR NTS REPORTING

\begin{tabular}{|c|c|c|}
\hline Contractor & No. of NTS Reports & Enforcement Actions \\
\hline Ames Laboratory & 0 & 0 \\
\hline Argonne National Laboratory-East & 2 & 0 \\
\hline Argonne National Laboratory-West & 1 & 0 \\
\hline Battelle - PNNL & 4 & 1 PNOV w/o $\mathrm{CP}^{\text {iit }}$ \\
\hline Bechtel - Hanford & 2 & 0 \\
\hline Brookhaven National Laboratory (BNL) & 3 & $\begin{array}{c}0 \\
\text { (but 1 PNOV to Subcontractor) }^{\text {iv }}\end{array}$ \\
\hline EG\&G - Las Vegas & 0 & 0 \\
\hline EG\&G - Mound & 3 & 0 \\
\hline Fermi National Accelerator Laboratory & 0 & 0 \\
\hline Fernald (FERMCo) & 5 & 0 \\
\hline Idaho/Lockheed-Martin & 9 & 0 \\
\hline Kaiser Hill & 11 & $\begin{array}{c}1-\text { PNOV w/CP } \\
(+1 \text { PNOV w /CP to Subcont.) })^{v}\end{array}$ \\
\hline KC Allied Signal & 0 & 0 \\
\hline Lockheed Martin Energy Research (ORNL) & 2 & 0 \\
\hline Los Alamos National Laboratory (LANL) & 8 & $1 \mathrm{PNOV} \mathrm{w} / \mathrm{o} \mathrm{CP}^{17}$ \\
\hline Lockheed-Martin Science Center (Pinellas) & 2 & 0 \\
\hline Lockheed Martin Energy Systems (Oak Ridge) & 4 & 0 \\
\hline Mason-Hanger & 9 & 0 \\
\hline Princeton Plasma Physics Laboratory & $\overline{0}$ & 0 \\
\hline REECO & 0 & 0 \\
\hline RSN & 0 & 0 \\
\hline Rust-Geotech & 0 & 0 \\
\hline Sandia National Laboratory (Lockheed-Martin) & 4 & $1 \mathrm{PNOV}$ w/CP \\
\hline Stanford University & 1 & 0 \\
\hline Lawrence Livermore National Laboratory & 3 & 0 \\
\hline Lawrence Berkeley National Laboratory & 2 & 0 \\
\hline West Valley Nuclear Services & 1 & 0 \\
\hline Westinghouse Hanford & 11 & $1 \mathrm{PNOV}$ w/CP \\
\hline Westinghouse Savannah River Company & 15 & 0 \\
\hline
\end{tabular}




\section{CHANGES AND IMPROVEMENTS}

' NTS Reports Through December 31, 1996 for DOE's principal (Management and Operating) contractors. Subcontractors would file noncompliance reports through their respective contractor, who has responsibility for oversight and management of subcontractor activities including compliance.

A larger number of NTS reports by a contractor does not correlate to a poor performer, but could be indicative of a more aggressive compliance determination program.

ii Formal enforcement actions of a PNOV (Preliminary Notice of Violation) with or without a CP (civil penalty). DOE has taken a number of less-formal enforcement actions such as enforcement conferences or issuance of Enforcement Letters (a form of warning) in at least ten other cases.

iii PNNL and LANL are specifically excluded from application of civil penalties by PAAA statute.

iv A subcontractor to BNL (PETSCO) received a PNOV. No civil penalty was assessed since a subcontractor to a notfor-profit Laboratory is also exempt from civil penalties by the PAAA statute.

v A PNOV with civil penalty was also issued to a Kaiser-Hill subcontractor, Safe Sites of Colorado., a venture of Westinghouse Electric and Babcock \& Wilcox. 